\title{
El sistema de cargos en Mesoamérica: de fundación piadosa a institución político-religiosa
}

\author{
Eloy Gómez Pellón \\ Universidad de Cantabria \\ gomezel@unican.es
}

Recibido: 6/11/2014

Aceptado: 28/7/2016

\section{RESUMEN}

El presente texto analiza algunas de las explicaciones que, hasta el presente, se han elaborado para entender la existencia del llamado sistema de cargos o de la denominada jerarquía cívico-religiosa en el ámbito mesoamericano. Después de reparar en el hecho de que el interés por el tema naciera básicamente unido a los peasant studies de los años veinte del siglo pasado, el texto muestra cómo, en las décadas siguientes, se fueron ofreciendo interpretaciones muy variadas del sistema de cargos, que lo hacían compatible no sólo con la tradicional perspectiva de la comunidad homogénea, sino también con la perspectiva de la comunidad heterogénea. La discusión se vería enriquecida con la sugestiva suposición de que el sistema de cargos tendría un fundamento prehispánico. Sin embargo, el presente trabajo defiende la idea de que las pautas culturales introducidas por los colonizadores transformaron la sociedad prehispánica, para ser posteriormente perpetuadas por la ideología de la colonialidad. Éste fue el caso de la cofradía que, como fundación piadosa, terminó por convertirse en una institución nuclear de la vida local, dotada de un claro papel integrador y de un fuerte sentido identitario en una sociedad multiétnica. El sistema de cargos de Mesoamérica sería la consecuencia de las sucesivas presiones ejercidas sobre la vieja cofradía por el poder real y, sobre todo, por el poder republicano, por vía del laicismo y de la desamortización en el caso mexicano, cuyos efectos más evidentes consistirán, en primer lugar, en la potenciación del carácter político de la cofradía sin merma del religioso; y, en segundo lugar, en el reforzamiento del patronazgo como pilar fundamental de la institución. Así quedó conformada una estructura piramidal y clientelar que aún conserva muchos de los elementos que definieron tradicionalmente a las cofradías, tanto en España como en la América hispana.

Palabras clave: Sistema de cargos, jerarquía cívico-religiosa, cofradías, sociedades campesinas, Mesoamérica.

\section{The Cargo System in Mesoamerica: From its Ecclesiastic Foundation to Political-Religious Institution}

\begin{abstract}
The present text studies some of the explanations that, to date, have been put forward to understand the socalled cargo system or civil-religious hierarchy in Mesoamerica. After noting that interest in the topic basically began in connection with peasant studies in the 1920s, the text shows how very varied interpretations of the cargo system were proposed in the following decades. These made it compatible not only with the traditional view of a homogeneous community but also with the perspective of a heterogeneous community. The discussion was enriched with the suggestive supposition that the cargo system possessed a pre-Hispanic origin. However, the present paper shows that the cultural models introduced by the colonisers transformed preHispanic society and were later perpetuated by the ideology of coloniality. This was the case of the cofradia or guild, which, as a pious foundation, finally became a nuclear institution in local life, endowed with a clear integrating role and a powerful identitarian sense in a multi-ethnic society. The cargo system in Mesoamerica would be the consequence of successive pressure exercised on the old cofradías by royal power and, above all by republican power, through secularism and disentailment in the case of Mexico. The most apparent effects consisted first of the increasingly important political nature of the cofradía, without its religious character weakening; and secondly of strengthening patronage as a fundamental pillar of the institution. In this way a pyramidal and clientelist structure was shaped, still conserving many of the traits that traditionally defined the cofradías, both in Spain and in Latin America.
\end{abstract}

Key words: cargo system, civil-religious hierarchy, cofradias, peasant societies, Mesoamerica.

Sumario: 1. Introducción. 2. Variaciones en torno a la comunidad campesina. 3. La teoría del origen prehispánico del sistema de cargos. 4. La teoría colonial-republicana. 5. Conclusión. 6. Referencias bibliográficas. 


\section{Introducción}

Los años veinte incorporan en los Estados Unidos, y progresivamente en otras partes del mundo, un objeto de estudio nuevo para la antropología, que es el de los campesinos. La publicación del estudio de Robert Redfield (1930) Tepoztlan. A Mexican Village marca el inicio de esta tendencia llamada a perdurar. Acogido al paradigma funcionalista, escasamente representado en la antropología norteamericana, e influido por la Escuela de Chicago, Redfield descubre en Mesoamérica la sociedad campesina, fijándose para ello en la vida en una comunidad folk, esto es, aislada, homogénea, pequeña y pobre, cuyos miembros viven en condiciones de subsistencia. Redfield (1973a, 1973b), confirmaría, además, la idea reiterada por Kroeber (1923, 1948) de que el campesinado era «parte sociedad y parte cultura», para enfatizar su pertenencia a una sociedad mayor que les proporciona su marco de vida. La teoría de la «comunidad homogénea» acabaría siendo tan poderosa, sin duda debido a la sencillez con la que se había elaborado el marco teórico de la misma durante décadas, que el paradigma ni siquiera ha desaparecido por entero en nuestros días. Téngase en cuenta que este modelo de la homogeneidad fue defendido desde muchos puntos de vista, empezando por el que sostiene la especificidad de la economía campesina (Chayanov 1974 [1925]), siguiendo por el que podemos llamar cognitivo (Foster 1967), y concluyendo con el institucional (Wolf 1957, 1971). La solidez con la que se mantuvo la perspectiva de la «comunidad» campesina homogénea sólo comenzó a ceder progresivamente a partir de los años sesenta, cuando algunos antropólogos, recurriendo a hipótesis distintas, y mediante técnicas de observación diferentes, cuestionaron, cada vez con más insistencia la teoría. La primera de las grandes brechas la había abierto Oscar Lewis, el antropólogo que toma la decisión de realizar un estudio antropológico, dos décadas después del llevado a cabo por Redfield, en el mismo lugar, titulado Life in a Mexican Village: Tepoztlán Restudied (1951). Sin embargo, Lewis encontró una sociedad campesina que no era tan homogénea como la que había supuesto Redfield, ni tan cerrada, ni tan aislada.

\section{Variaciones en torno a la comunidad campesina}

La existencia teórica de comunidades campesinas, cerradas e independientes, había procurado a la antropología el sucedáneo de las viejas comunidades primitivas. Por otro lado, se trataba de una teoría que rimaba con la tradicional aceptación de la clara separación entre el ámbito rural y el urbano. Más aún, y en efecto, la teoría de la «comunidad homogénea» concordaba con el uso de técnicas de observación sencillas, a partir de la suposición de que las distintas unidades domésticas eran extremadamente parecidas entre sí, salvo en los aspectos debidos a la pura contingencia, al azar genealógico, etc. La subsistencia sustentada en la relativa pobreza de medios era la hipótesis de partida que orientaba cualquier estudio, de acuerdo con el modelo teórico consolidado en los estudios campesinos hasta 1960. A pesar de que Eric Wolf (1957) situó el problema en un escenario nuevo, al apreciar que existían «comunidades abiertas al exterior», el modelo de la homogeneidad campesina no fue puesto en 
duda $\mathrm{y}$, antes bien, subsistió con relativa facilidad en la antropología de la segunda mitad del siglo XX. En cualquier caso, y por vez primera, Wolf negaba la existencia de un modelo teórico rígido de comunidad campesina, aunque confirmaba la existencia de un tipo de comunidad cerrada y corporativa, producto de la colonización exterior o de la interior, que, en suma, coincidía con el estudiado hasta ese momento. Tanto es así que Frank Cancian (1991: 185) califica a Wolf como el más influyente teórico de la homogeneidad, aun admitiendo que en las antropologías de Foster y de Chayanov latía, asimismo, y por igual, la sustancia de la homogeneidad.

La propuesta de Wolf, a la que se acogería en buena medida Cancian, no dejaba de ser un tanto sorprendente, al aceptar la doble existencia de comunidades campesinas autárquicas y cerradas, por un lado, y, por el otro lado, la de comunidades campesinas abiertas en algún grado al exterior (con la consiguiente contradicción representada por la «comunidad abierta»), aunque resultaría estimulante de cara a la elaboración de hipótesis (Gómez Pellón 2011: 74-79). Es evidente que, de alguna manera, y con independencia del grado de apertura de la comunidad, se trataba de preservar la supuesta homogeneidad de la comunidad campesina. Mientras se cedía admitiendo la dificultad para inducir la generalización de la comunidad cerrada, habida cuenta de la gran cantidad y variedad de sociedades campesinas existentes en el mundo, se mantenía la generalización de la comunidad homogénea, independientemente del grado de apertura de la misma. Sin embargo, es importante señalar aquí que la idea de la comunidad homogénea tenía causa, especialmente, en Redfield, quien había creído estar seguro de la existencia en Tepoztlán de la Gemeinschaft, tal como había denominado Tönnies en 1887 a la sociedad tradicional, gobernada por las relaciones simples establecidas entre sus miembros, a partir de una voluntad natural, por contraposición a la Gesellschaft o sociedad moderna regida por la voluntad racional (Tönnies 2009). También es importante recordar que el trabajo publicado por Lewis (1951) sobre el mismo Tepoztlán no había confirmado la presencia de la comunidad homogénea, tipo Gemeinschaft, tal como había supuesto Redfield. Por tanto, la propuesta de Wolf, encontrando comunidades abiertas, era un primer intento por resolver la contradicción.

Frank Cancian (1972) realizó un minucioso estudio en un asentamiento del área maya del sureste de México, en Zinacantán, a partir de 1960, en un momento en el que estaba arreciando la discusión acerca de la teoría de la homogeneidad campesina, llegando a la conclusión de que el mismo respondía con relativa fidelidad al perfil trazado por Wolf de la comunidad cerrada y corporativa, aunque introduciendo algunas importantes novedades. El asociacionismo religioso y ritual, en un contexto católico, ilustra lo que es un sistema de esta índole. Explica Cancian que la reputación comunitaria de un hombre depende del lugar que éste ocupa en el sistema de cargos, en alusión directa a las obligaciones que los hombres adquieren con motivo de la celebración de las fiestas patronales, vertebradas en torno a la cofradía local, con la cual sellan un singular y dispendioso compromiso. La carrera de un hombre en una cofradía se desarrolla en cuatro niveles, cada uno de ellos compuesto por toda una larga serie de cargos u obligaciones que el titular ha de sobrellevar para alcanzar el máximo prestigio dentro de la comunidad.

Se trata de cargos que se asumen por un tiempo corto, generalmente de un año de duración, en el curso del cual los compelidos han de cumplir con cargas tanto 
más pesadas cuanto más alto es el nivel, y que pueden consistir en la financiación, organización y materialización de dispendiosas fiestas en beneficio de la comunidad entera. La aceptación de los cargos del cursus hornorum está sólidamente vinculada con la reputación de ese hombre en el seno de la comunidad. Más sorprendente aún es que en muchos lugares de Mesoamérica el sistema de cofradías (Cancian 1972, 1991, 1996) esté ligado con el sistema de cargos civiles, de modo que los hombres que participan en el mismo van alternando sus obligaciones en la cofradía y en la administración local, dejando algún espacio de tiempo entre unos y otros. Dada la variedad de la casuística, pero también la coincidencia de los caracteres fundamentales del sistema de cargos, a la definición mínima del sistema de cargos se la conoce como típico sistema de cargos (vid. Korsbaek 1996: 67-82).

Se puede decir que tal sistema proporciona al individuo un estatus, que a menudo es dominante, y siempre posee una gran significación en el contexto de la comunidad. En realidad, el sistema zinancanteco de cofradías, como denomina Cancian (1972, 1991: 187, 1996) al sistema de cargos estudiado por él mismo en los Altos de Chiapas, no es diferente de otros existentes en el resto de Mesoamérica, bien con esta última denominación (vid. Korsbaek 1996, 2009), o bien con los nombres sinónimos de sistema de escala o de escalafón (Buchler y McKinlay 1996; Cancian 1996; Carrasco 1979), sistema de fiestas (De Walt 1996; Smith 1981), sistema de mayordomías (Aguirre 1953), y jerarquía civil-religiosa (Buchler y McKinlay 1996; Cámara 1996; Carrasco 1952, 1979; Chance y Taylor 1985; Foster 1987; Korsbaek 1987; Nash 2009; Rus y Wasserstrom 1980; Sepúlveda 1974; Tax 1937; Topete 2009; Vogt 1966, 1979); ni siquiera es distinto de los sistemas existentes en el resto de Iberoamérica (Aguirre 1953; Buchler 1980; Cámara 1996; Smith 1981), con análogos nombres a los citados, y a los que se añade el de sistema de varas (Tschopik 1947). Ciertamente, Cancian nos explica minuciosamente el complejo sistema de cargos existentes en Zinacantán, como exponente de lo que se está señalando.

Para hacernos una idea de la complejidad del sistema en Zinacantán, basta decir que sólo en el primer nivel existen alrededor de 35 cargos, cuya culminación abre la puerta a un segundo nivel en el que se hallan 12 cargos, que a su vez conducen a los 6 cargos del tercer nivel y, por último, a uno de los dos cargos del último nivel, esto es, del cuarto. Por cierto, al mismo tiempo que realizaba su investigación Cancian, este mismo asentamiento estaba siendo estudiado por Evon Vogt, otro de los teóricos del sistema de cargos $(1966,1979)$, y casi coincidiendo con Robert Wasserstrom (1989), otro excelente conocedor del tema. Es tal el prestigio asociado a cada uno de estos cargos, in crescendo según el nivel, que es necesario esperar hasta cerca de los cuarenta años para iniciar la carrera en el primer nivel, lo cual significa que el aspirante a los puestos más altos no tiene tiempo que perder, y que son muchos los hombres que mueren antes de alcanzar su objetivo, en el recorrido de su particular cursus honorum, es decir, de su singular escalafón de responsabilidades. El hecho de que estemos, frecuentemente, ante lo que Wolf (1981) denomina con el nombre de una comunidad campesina, corporativa y cerrada, se evidencia en el uso de la lengua común, en el sentimiento identitario y en su sistema local de cargos, y nos ilustra acerca de lo que los institucionalistas han apreciado en relación con estas comunidades campesinas. 
En el sorprendente análisis de Cancian (1972) hay algo que llama más aún, si cabe, la atención. La conquista de los sucesivos cargos está asociada a los importantes costes que implica el mantenimiento del ritual, y que incluye la conservación de capillas, fiestas, ceremonias de distinta índole, etc. El culmen de la mayordomía, por ejemplo, supone un notable dispendio, muy superior a menudo al que nos podríamos imaginar. En este sentido, Cancian explica que en 1960 un mayordomo-rey gastaba en el año de su función alrededor de 10.000 pesos (3.000 dólares americanos), que trasladados a nuestra época arrojarían un notable capital. Dado que no es posible reunir con facilidad esa cantidad en el interior de la comunidad, muchos hombres se afanan en conseguirlo trabajando lejos de su casa, en ocasiones migrando a los Estados Unidos (Cancian 1991: 187). Sin embargo, el gasto, por lo que tiene de reconocimiento y de adquisición de prestigio y reputación, para el hombre que lleva a cabo la proeza y para su familia, se da por muy bien empleado. Si este hombre llegara al nivel alto de la jerarquía, especialmente al cargo más elevado de este nivel, convirtiéndose en un pasado, en un principal, $o$ en un anciano, la comunidad entera le reconocería la máxima reputación, de modo que sería exonerado, incluso, del cumplimiento de ciertas obligaciones tributarias o extratributarias (Cancian 1991: 187; Nash 2009). Con todo, es Cancian el que nos recuerda que los reconocimientos fiscales o parafiscales por parte de la comunidad no son más que una minucia insignificante en relación con el capital invertido.

En efecto, da la impresión de que en el caso de Zinacantán estaríamos ante una comunidad corporativa y cerrada. Hasta podríamos pensar que todo este sistema constituye el artificio que la comunidad precisa para mantener su cohesión externa y para redistribuir la riqueza de los agraciados, los cuales son empujados para que gasten generosamente sus bienes. Sin embargo, una de las respuestas surgidas a la percepción de la homogeneidad en su vertiente institucional vino, precisamente, del lado de Cancian $(1972,1989)$, tratando de hallar, igualmente, una conciliación teórica. Este último advirtió que Wolf (1971) en su trabajo de 1966 había puesto el acento en el aspecto local y en el supuesto aislamiento de las comunidades campesinas, pero también en el llamado mecanismo nivelador, esto es, en la existencia de un automatismo mediante el cual, cuando aflora la desigualdad, las instituciones existentes en la sociedad campesina igualan a los individuos que las integran, destacando entre ellos el que podemos denominar de filantropía reforzada en expresión del propio Wolf. En realidad, según explica Leif Korsbaek (2009: 10), el concepto de mecanismo nivelador fue enunciado simultáneamente, en 1966, por Wolf (1971) y Nash (1996). Mediante presiones sociales, las instituciones logran que los individuos que acumulan mayor prestigio y reconocimiento personal patrocinen rituales colectivos a sus expensas, permitiendo de este modo algo similar a un reparto más equitativo de la «riqueza». Al mismo tiempo, el sistema de cargos posee una fuerte dimensión religiosa, que actúa como definidora de la comunidad, que es fuente de identidad, y que actúa como factor de resistencia cultural, impidiendo la introducción de cambios (Korsbaek 2009: 10).

Ahora bien, frente al llamado paradigma del sistema de cargos que alberga la teoría del levelling mechanism o mecanismo nivelador, el propio Cancian elaboró en 1967 un modelo explicativo, conocido como de estratificación, que hunde sus raíces 
en la sociedad colonial (Cancian 1996: 210-214). Cancian no negaba la existencia de la comunidad campesina homogénea, aunque creía que había distintos tipos de comunidades campesinas, como veremos. Sin embargo, se separaba en la idea del mecanismo nivelador. Lo que haría el sistema de cargos no sería aliviar o difuminar las tensiones propias de la desigualdad, sino consagrarlas. Esta razón explica, como ha mostrado muy acertadamente Korsbaek (2009: 11), que la mayor parte de los trabajos que adoptan esta teoría, poseen, complementariamente, una marcada dimensión histórica que interesa especialmente en relación con la perspectiva que se mantiene en el presente texto. Más aún, en el acalorado debate que se mantiene sobre este asunto a lo largo de los años sesenta intervendría Marvin Harris (1964) para defender el llamado modelo de expropiación que contempla la organización de la comunidad campesina latinoamericana como efecto del propósito de los colonizadores para evitar el retorno al control indígena (vid. Korsbaek 2009: 12). Según Harris, lejos de la suposición de que bajo las comunidades campesinas seguía latiendo la vida indígena, aquéllas quedaron envueltas hasta la saciedad por la ideología del colonialismo. Esta última teoría ha sido defendida más tarde con mucha fuerza por los partidarios de la tesis de la colonialidad, como clasificación social, universalmente básica, impuesta por el colonialismo a partir del siglo XV (Mignolo 2003, 2007; Quijano 2000, 2007).

A propósito de la comunidad homogénea y del sistema de cargos, durante mucho tiempo se ha venido sosteniendo que el trabajo publicado por Sol Tax en 1937 habría sido el primero en prestar atención al sistema de cofradías en Mesoamérica, abriendo, al mismo tiempo, la posibilidad de las explicaciones más diversas a la existencia del hecho. Hoy en día se piensa que la primera referencia nítida acerca del asunto es la de Carlos Noriega Hope (1922), aunque el mismo, por lo que parece, pasara desapercibido para los antropólogos posteriores, hasta que, a finales del siglo XX, se reparara en el hecho. Es lo cierto que, años más tarde de que se publicaran estos dos trabajos, a partir de 1952, y al mismo tiempo que Fernando Cámara (1996 [1952]), Pedro Carrasco publicará sucesivos textos en los que se inclina, como explicación histórica del sistema de cargos o de cofradías, o de la jerarquía cívico-religiosa, según la denominación preferida por este último, por la existencia de una neta influencia de la propia tradición mesoamericana anterior a la llegada de los españoles, aunque no niega la impronta de las instituciones españolas en este sistema cívico-religioso (Carrasco 1979: 325-326). El sistema descrito por Carrasco, como propio de las comunidades tradicionales de indios de Mesoamérica, se define por la existencia de una jerarquía que combina los cargos civiles y ceremoniales de la organización de la vida local en una única escala de cargos anuales. Los hombres de la comunidad tienen que participar en el sistema y todos tienen la oportunidad de progresar en los escalones que componen la institución, si bien no todos pueden alcanzar los cargos correspondientes a los últimos niveles.

Es el propio Carrasco (1979: 323) quien llega a calificar el sistema como «un tipo de democracia, en el que todos los cargos están abiertos a todos los hombres y en que el funcionamiento de la escala tiene como resultado que todo el mundo participe por turno en las responsabilidades de los cargos». Carrasco, al igual que años más tarde Cancian $(1972,1991)$, enfatiza la progresiva reducción de los cargos a medida que se progresa en la escala. Con todo, en el último nivel, los puestos de la parte religiosa 
(mayordomías) y los de la parte civil (regidores y jueces) resultan tan apetecidos que, a pesar de la dificultad que entraña su obtención, muchos hombres no cejan en el empeño. Cuando se trata de ciudades y de villas, y éstas están divididas en distritos, todos ellos tienen sus correspondientes cargos, entre los cuales no faltan los que se hallan en los niveles superiores de la jerarquía. Ahora bien, en este caso se trata de cargos que van solidariamente unidos con importantes responsabilidades (patronazgo de las fiestas, organización de banquetes ceremoniales, etc. relacionados con la transmisión del cargo, tanto en la esfera religiosa como en la civil), frente a los cargos del nivel más bajo que son claramente serviles (recaderos ceremoniales, barrenderos y vigilantes de la villa o de la ciudad).

Cancian $(1972,1976)$ observó que esta situación, además de contribuir a fijar las fronteras de lo local, a efectos de trazar la diferencia con el entorno, contribuye a mantener la solidaridad social y el aislamiento cultural del lugar, de modo que estas instituciones rituales «tipifican el aspecto interior de las comunidades campesinas». Ciertamente que, en los casos en los que está presente este sistema cívico-religioso, nos hallamos ante comunidades campesinas que Wolf (1981) clasificó como corporativas y cerradas. La explicación de que existan tales tipos de comunidades, según este último, se hallaría en que en las mismas ha operado una polarización, bien por oposición a la colonización que, procedente del exterior, afecta a la sociedad entera que sirve de marco a la campesina, o bien como resistencia frente a la colonización interna, desencadenada en su propia sociedad. No obstante, y si bien las comunidades campesinas de Mesoamérica y de Java, que fueron las estudiadas por Wolf, son corporativas y cerradas, debido a su historia colonial, cuando no se producen las condiciones de colonización señaladas las comunidades campesinas adoptan un carácter abierto, tal como descubre Wolf en algunas partes de América Latina y de otras regiones del mundo.

Ahora bien, en el razonamiento de Wolf, la existencia de comunidades campesinas cerradas es plenamente compatible con la perspectiva de la homogeneidad propia de la pobreza campesina, subrayando así sus rasgos igualitarios. Según Wolf (1981), en la senda del planteamiento de Tax (1936), las instituciones de la vida comunitaria canalizan fuertes presiones, que empujan a las personas a la participación en los rituales comunitarios, de manera que la riqueza invertida por los más ricos revierta favorablemente en los más pobres, provocando la nivelación general. La observación, sin embargo, es discutible, sobre todo tras observar el funcionamiento de las instituciones cívico-religiosas. Ciertamente, un examen más minucioso descubre, por el contrario, rasgos jerárquicos, que llevan a Cancian (1991: 202-203) a pensar que Zinacantán, como otros muchos lugares, pudiera estar más cerca de la heterogeneidad de la comunidad campesina, por más que se tratara de una comunidad corporativa cerrada. Los hombres más ricos no sólo progresan en el escalafón de responsabilidades de la cofradía sino que siguen siendo más ricos. Los integrantes de los sucesivos niveles se van ordenando con relación a los que ocupan los niveles superiores y, más aún, la dificultad para escalar hasta los puestos más altos del nivel superior implica la posesión de un estatus superior en el sistema de posiciones de la sociedad local. De ello se sigue que los rasgos de carácter igualitario se van combinando con otros 
de orden profundamente jerárquico, todos los cuales, en su conjunto, proporcionan la auténtica medida de un sistema de cofradías o de cargos.

\section{La teoría del origen prehispánico del sistema de cargos}

Según explica Carrasco (1979: 323-325), los rasgos de la organización política, ceremonial y económica de época precolombina en Mesoamérica eran similares a los del sistema moderno de la escala cívico-religiosa, y concreta como significativos los siguientes: a) existencia de una escala de estatus jerárquicamente clasificados; b) la posibilidad para un amplio grupo de individuos de ascender en esta escala; c) la vinculación de la escala a la estratificación social; d) las numerosas implicaciones económicas del sistema. Para mostrar este hecho en el período precolombino, Carrasco recurre a la información que proporciona, entre otros, el dominico Fr. Diego Durán (Historia de las Indias de Nueva España e islas de Tierra Firme, cuyo manuscrito, redactado en la segunda mitad del siglo XVI, fue transliterado en 1867), que pasa por ser uno de los más fidedignos informantes acerca de las sociedades mesoamericanas en el siglo XVI, junto con el franciscano Bernardino de Sahagún (Historia general de las cosas de Nueva España, 1540-1585), que es el otro autor que Pedro Carrasco sigue, aunque complementariamente también considera las informaciones de cronistas como Alonso de Zorita, Gómez de Orozco y otros. Así, Carrasco utiliza en 1961 datos procedentes del área azteca (1979: 325-326). Recuérdese que los textos de referencia en la época eran el de Tax (1937) sobre el área maya de Guatemala, y el de Cámara (1952), que incluía información del área maya y del área azteca. Carrasco señala en su trabajo que, aunque utiliza datos procedentes de los aztecas, en la totalidad de las áreas de Mesoamérica sucedería algo parecido. Curiosamente, hoy sabemos, verificando la suposición de Carrasco, que el típico sistema de cargos está extendido por toda Mesoamérica, «sin dar preferencia a ninguna región o cultura en particular, y no se limita a una pequeña región, por ejemplo Chiapas, Michoacán o Guatemala» (Korsbaek 1990, 1996: 67-85). El hecho no es nimio, y debe tenerse en cuenta, porque las diferencias de sustrato histórico (que Carrasco minimiza), sobre las que operó la colonización no impidieron la constitución de idénticas prácticas institucionales, tal como se evidencia en el caso del sistema de cargos. Se deduce con ello que, efectivamente, o eran muy similares en ciertos aspectos las distintas tradiciones culturales de Mesoamérica, o la extensión del sistema de cargos por todo el ámbito mesoamericano se ha producido, fundamentalmente, por la vía colonial. Más aún, recuérdese lo que se apunta más atrás a propósito del desbordamiento del sistema de cargos, en su rica casuística, sobre la totalidad de Iberoamérica (Aguirre 1953; Smith 1981).

Pero, volviendo al trabajo de Carrasco (1979: 326-331), que es el que justifica los orígenes precolombinos del sistema de cargos, al menos en lo sustancial, parece que el objetivo del ascenso social y el de la adquisición de títulos eran parte indisociable de las actitudes culturales de la sociedad azteca, gracias a las tres vías fundamentales para la progresión en el status: la guerra, el sacerdocio y el comercio. Así, la movilidad ascendente en el estatus militar y en el religioso se iniciaba en las llamadas casas de los hombres, una de las instituciones que vertebraba la sociedad prehispánica. 
Sabemos que existían dos tipos de casas de hombres, entendiendo por tal la institución donde se educaban los jóvenes varones. Mientras que los jóvenes plebeyos se formaban en las casas de juventud (telpochcali), donde eran instruidos en la milicia y en las obras públicas, los jóvenes nobles se formaban preferentemente en el segundo tipo de casas de hombres, en las calmecac (dispuestas en hilera), donde realizaban sus estudios especializados preferentemente en lo religioso, y complementariamente en lo militar y en determinados oficios de la vida civil.

De acuerdo con la información que proporciona Durán (1995), concordante con la de Sahagún (1938) y con la de otros, la actividad militar y la sacerdotal estaban fuertemente conectadas, aunque comportaban dos itinerarios diferentes para los aspirantes. Los hombres jóvenes dejaban la casa de los hombres después de los veinte años y antes de los treinta, cuando podían optar entre su carrera de ascensos en la guerra, acaso más rauda, y la gestión civil o religiosa en los distritos de su ciudad, los cuales eran hereditarios con cierta frecuencia, hasta la conclusión de su cursus honorum a los 52 años, cuando pasaban a gozar de un acusado reconocimiento, especialmente tras haber alcanzado la dignidad de jefes de distrito. Los ancianos de cada distrito, o calpulhuehuetque, eran tenidos por consejeros del jefe de distrito y conformaban el grupo que velaba por el ceremonial de su distrito. Por su parte, la carrera religiosa comenzaba a menudo en el pequeño sacerdocio, desempeñando tareas serviles, y progresaba en los templos consagrados a las distintas deidades, siendo posible alcanzar el grado de sumo sacerdote, o serpiente emplumada, para lo cual se reservaban dos puestos. Como la escala religiosa estaba conectada con la militar, era posible el paso a la milicia. Los sacerdotes veteranos podían recibir también encargos del gobierno civil, incluso en los puestos más elevados de la jerarquía. Los distintos grados, en la carrera militar o en la religiosa, iban asociados con expresiones estéticas (vestimenta, peinado, tocados, adornos corporales, etc.

Todo lo dicho hasta aquí conduce a Carrasco $(1952,1975,1979)$ a pensar que el sistema de jerarquía cívico-religiosa, que venía siendo examinado por la antropología desde los años treinta del siglo pasado, podría guardar una relación estrecha con la tradición precolombina del área mesoamericana. Algunas prácticas conservadas en la actualidad entre los chinantecas y los mixe en materia de cofradías parecen abonar esta última hipótesis. A propósito, entre el primer texto sobre el asunto, que puede ser el de Tax (1937), o incluso el de Noriega Hope (1922) si se reconoce su temprano acercamiento al tema, y el presente, observaremos que el área del sistema de cargos no ha hecho sino ensancharse. Sólo a partir de Carrasco (1952, 1979), al prestar especial atención a las regiones náhuatl, otomí, mazahua y purépecha, comenzó a vislumbrarse la amplitud geográfica un fenómeno que hoy trasciende con creces su ubicación inicial en el área maya del sur y sureste mexicano (Chiapas, Campeche, Quintana Roo y Yucatán) y de Guatemala, para alcanzar hacia el Sur a Belice, El Salvador y Honduras, e incluso a Nicaragua, y por el Norte a los Estados de Oaxaca, Guerrero, Michoacán, Puebla, Morelos, Tlaxcala y Veracruz, hasta el Estado de México y el Distrito Federal, y más al Norte, a los Estados de Jalisco, Nayarit, Durango y Chihuahua, entre otros. No es exagerado decir (Korsbaek 1996: 68), merced a una investigación cada vez más rigurosa, que el típico sistema de cargos se desparrama sobre la práctica totalidad de Mesoamérica y la trasciende. 
Volviendo a Carrasco (1979: 325-326), éste señala que los rasgos de la organización política, ceremonial y económica precolombina «son similares al sistema moderno de escala cívico-religiosa», considerando que «lo que nos importa es la existencia de una escala de estatus jerárquicamente clasificados» y la progresión de los individuos en esa escala. Remarca el autor el hecho, sin embargo discutible, de que el sistema cívico-religioso de las comunidades indias mesoamericanas es acusadamente democrático, en el sentido de que no hay restricciones de acceso, y de que todos los postulantes pueden recorrer el complejo cursus honorum, al menos en los primeros niveles, de manera que algunos pueden alcanzar la cima, como sucede con los campesinos actuales que participan en el sistema de cargos. El hecho de que el sistema cívico-religiosos actual aúne lo religioso y lo civil en alguna medida constituye uno de los aspectos que aconsejan a P. Carrasco ahondar en la hipótesis de la continuidad prehispánica a partir de un supuesto parecido. Otros aspectos, como la duración anual de los cargos, inducen igualmente al citado autor a suponer una estrecha relación entre el sistema de cofradía actual y la organización de las sociedades indígenas en Mesoamérica. Es por ello que dice: «sin negar la indudable aportación española a su evolución, este artículo pretende subrayar los antecedentes anteriores a la llegada de los españoles y mostrar cómo conformaron la introducción de la organización municipal española en el estado de cosas del gobierno colonial» (Carrasco 1979: 325).

Muchas de las similitudes entre el sistema de escala antiguo y el moderno podrían proceder, a juicio de Carrasco (ibid.: 334-336) y de otros autores (Favre 1973; Macleod 1983), de la estrategia colonizadora de los españoles. En el área mesoamericana, donde existían estructuras estatales precoloniales, los colonizadores optaron por adoptar en los municipios el denominado gobierno dual, según el cual los funcionarios del régimen colonial se incorporaban a la administración municipal compartiendo poder con el antiguo grupo dominante (Carrasco 1952, 1979: 334). A fin de conservar las estructuras fiscalizadoras, y tratando de pactar con las elites dominantes, se prefirió conciliar el viejo sistema con el nuevo, de manera que los antiguos funcionarios y los nuevos terminaron por constituir el cuerpo administrativo de la ciudad (vid. Aguirre 1953). Fue así como se conservaron prácticas en el acceso a niveles y a grados en la vida ceremonial y hasta en ciertos aspectos de la vida civil. Más aún, en los niveles inferiores de la organización municipal se produjo una total continuidad. Existen sobradas evidencias de que esto sucedió así al examinar las sociedades mesoamericanas actuales, en las que se siguen conservando prácticas administrativas y ceremoniales directamente heredadas de los viejos pobladores. Carrasco (1979: 334-335) pone como ejemplo el caso del Chiapas de aquel momento, a imagen y semejanza de lo que sucede en otros muchos lugares en el presente. Así, la cultura mesoamericana actual estaría presidida por costumbres y prácticas duales, esto es, de convivencia generalizada entre la tradición antigua y la moderna. En este sentido, Carrasco (ibid.: 334) muestra como en los Altos de Chiapas, en los años cincuenta del siglo XX, convivían en el gobierno municipal los funcionarios regidos por la ley del Estado y los funcionarios tradicionales, a modo de mezcla de elementos precolombinos y coloniales.

Por lo que sabemos, aunque la función militar y la religiosa eran las sendas más habituales del progreso social en la sociedad azteca, también el comercio lo era (ibíd: 331). Existían en la tradición indígena agrupaciones de jóvenes mercaderes que rea- 
lizaban expediciones mercantiles por encargo o con permiso de los mercaderes más poderosos. El éxito en el ámbito comercial, y más aún en lugares de conflicto y de guerra, procuraba méritos a los comerciantes, tanto mayores cuando la acumulación de capital permitía al comerciante destinar una parte de los beneficios a sostener algún templo o ciertos cultos religiosos. Este patronazgo generaba espléndidos réditos en la mejora de estatus del individuo que, gracias a su trabajo y a su tesón, pero también a su generosidad, alimentaba un modelo de personalidad valorado muy positivamente en la sociedad indígena mesoamericana. En el caso más extremo, el dispendio en el gasto podía provocar la ruina del benéfico individuo. A muchos de estos obstinados patrones no parecía importarles el hecho, al entender su actitud como una inversión para lograr el éxito personal y el reconocimiento social. Es Sahagún (1938) en la Historia general de las cosas de Nueva España (1547-1577) el que cuenta que, en aras de su causa preferida, estos dadivosos patrocinadores empeñaban solícitamente tierras y todo tipo de bienes (Sahagún 1938, I: 264-265).

Con su análisis histórico, Carrasco parece mostrarnos la inserción del actual sistema de cofradía en la tradición indígena, aunque este mismo autor no descuida la posible influencia de la tradición española en la costumbre (Carrasco 1979: 325). De hecho, en todo caso, se enfatiza la importancia del gobierno dual para entender los posibles orígenes del sistema cívico-religioso en las comunidades campesinas de Mesoamérica en nuestro tiempo, aunque sería preciso distinguir claramente el caso de las comunidades campesinas, de baja o nula estratificación social, del caso de las comunidades urbanas, en las cuales la estratificación social era muy acusada en los inicios de la colonización. De cualquier modo, el gobierno dual habría resultado inseparable de la gradual hibridación (vid. Gómez Pellón 2016) de los elementos culturales de procedencia indígena y española.

\section{La teoría colonial-republicana}

Hasta ahora hemos visto cómo algunos de los rasgos del sistema de cofradías existentes actualmente en Mesoamérica podrían hacernos pensar en una continuidad precolonial, como en su momento defendió Carrasco, por más que la suposición entrañe serias dudas. Sin embargo, los teóricos de la colonialidad (Mignolo 2003, 2007; Quijano 2007) defienden la idea de que las instituciones creadas por los colonizadores transformaron la sociedad, y una vez arraigadas permanecieron en el tiempo, como colonialidad del poder, generando una inercia que no hizo sino continuar y agrandarse tras la proclamación de las nuevas repúblicas, alimentando así la teoría del colonialismo interno. Ciertamente, muchos de los rasgos observados en las comunidades mesoamericanas del sistema de cofradías se parecen extraordinariamente a los que caracterizaron a las cofradías españolas en el pasado, y aún a los que las definen en el presente, tal y como señaló Isidoro Moreno (1981: 257-261) cuando se opuso a los planteamientos de quienes como Carrasco (1979: 325) atribuyen un antecedente precolombino a la jerarquía cívico-religiosa moderna. Admitiendo el parecido de las cofradías españolas y del sistema de cofradías de Mesoamérica, un interesante trabajo de Palomo (2001: 145-149) sobre las cofradías actuales de los pueblos tzeltales de 
Chiapas ha puesto de manifiesto que la cofradía, tras su constitución, a instancias de los colonizadores y por vía de los religiosos españoles, hubo de convertirse en el marco efectivo de la nueva religiosidad indígena, marcada por el profundo sincretismo. Da la impresión de que la cofradía, como institución privilegiada de la vida local, fue capaz de contener toda la cohesión social y la expresión identitaria que precisaba la comunidad indígena, por medio del rito y del ceremonial, sin menoscabo de su fuerza para canalizar el auxilio y la caridad, asimismo muy bien valorados por los nativos (Palomo 2004). De este modo, la cofradía habría sido, por un lado, instrumento eficaz de la colonización y, por otro y al mismo tiempo, espacio de identidad y resistencia indígenas, lo cual explicaría su éxito institucional y su persistencia.

El texto de Carrasco subraya el hecho de la continuidad directa que se habría producido en los niveles inferiores de la organización indígena, los cuales habrían sido mantenidos por los españoles a efectos de tributación y de organización de las obras públicas. A este fin, la administración municipal y las cofradías de los españoles se habrían constituido para adaptarse mejor a las prácticas indígenas de gobierno y a la estructura ceremonial (Carrasco 1961: 334). Sin embargo, frente al esfuerzo racionalizador de Carrasco para explicar la continuidad, que, en muchos aspectos, y también en el cívico-religioso, se produce, a su juicio, en las sociedades mesoamericanas, existen otras interpretaciones, como la que se muestra a continuación. Es muy posible que el sistema cívico-religioso de cargos, especialmente frecuente en Mesoamérica, guarde relación clara con las cofradías españolas, las cuales estaban en posesión de una larga historia en el momento de iniciarse la colonización del Continente americano. Las cofradías españolas, de origen medieval (Rumeu de Armas 1944), eran en el pasado, como aún en la actualidad, asociaciones voluntarias de laicos, constituidas con muy diversos fines e impregnadas por un poderoso espíritu religioso. Con estas mismas connotaciones existieron en distintas partes de Europa (Vincent 1994), de modo que, al tratarse de asociaciones con múltiples dimensiones, tales como la corporativa, la vecinal, la gremial, etc., se ha creído que sus raíces pudieran ser más antiguas aún. Entre los siglos XIII y XV estas fundaciones piadosas tuvieron una vida activa, que dio lugar a que se proyectaran sobre las actividades económicas y laborales, convertidas en gremios, algunos de los cuales llegaron al siglo XX con relativa lozanía. Todavía en el presente sobreviven en España las cofradías de pescadores y algunas más asociadas a distintos oficios, aparte de las tradicionales de carácter religioso cuyo número es muy elevado.

El mensaje fraternal que encierra la cofradía parece haber aconsejado a los colonizadores españoles su constitución en el Nuevo Mundo, tras haber sido probada previamente en España. El hecho de que la colonización americana coincidiera con la implantación de la Contrarreforma en el orbe católico, a partir de mediados del siglo XVI, explica el reforzamiento que acompañó al poder de estas fundaciones piadosas. Sabemos la importancia que, en rima con el nuevo espíritu que se predicaba, adquirió la acción de las órdenes mendicantes (franciscanos y dominicos), haciendo de la cofradía una de sus creaciones predilectas. La cofradía era ya por entonces una institución relevante de la sociedad española que, junto a la piedad y la caridad, logró hacer de la sociabilidad uno de sus valores más relevantes y atractivos. 
Fue de esta manera como, a buen seguro, la cofradía recibió, a partir de la segunda mitad del siglo XVI, un impulso aún mayor en América del que había recibido previamente, al convertirse la institución en una de las expresiones de la evangelización del Nuevo Mundo, dentro de la colonización total que llevaron a cabo los españoles. Sabemos, a través de los trabajos de Palomo (2004: 164) que, en el caso de Chiapas, los dominicos realizaron a partir del siglo XVI una intensa difusión de las cofradías entre los indígenas, que se prolongó hasta el XVIII, la cual resultó favorecida por el entusiasmo que las mismas despertaron en la población. Si bien la fundación de cofradías se llevó a cabo tanto entre los españoles y los ladinos como entre los indígenas, fue entre estos últimos donde tuvo lugar una progresión más intensa debido a la fuerte identificación que se produjo. A nivel local, la cofradía se convirtió en una de las manifestaciones más poderosas de la convivencia, de la colaboración, de la celebración de la fiesta patronal, del auxilio de viudas, huérfanos, inválidos, enfermos, etc., de la realización de exequias por los difuntos y de otros cometidos con repercusión local y municipal de gran importancia, al igual que sucedió en la España del Siglo de Oro, según nos explica Défourneaux (1983).

La evangelización se valió de instituciones como ésta para extender la cultura española por las tierras colonizadas, de manera análoga a como había sucedido antes en España con las tierras reconquistadas al Islam. El trabajo de Moreno (1981: 257-258) da cuenta de cómo el reino castellano había promocionado en Andalucía la llamada cofradía grupal, o étnica, impulsando la constitución de cofradías de negros en Sevilla, Cádiz, Jerez de la Frontera, el Puerto de Santamaría y en otros lugares, con resultados favorables para la integración de los grupos segregados, pero también para el mantenimiento de los mismos en forma de segmentos sociales. No en vano, en estos lugares hacen su emergencia cofradías de mulatos y de gitanos. Considerando que la cofradía encerraba una forma asociativa polivalente, apta para la difusión de la cooperación y la ayuda mutua, en un marco de espiritualidad cristiana, se explica que arraigara pronto en tierras americanas, especialmente en aquellas áreas en las que existía una sólida estructura organizativa previa, y por tanto en el área mesoamericana y en el área andina, quizás aprovechando en alguna medida la existencia de instituciones prehispánicas concurrentes.

La experiencia española en la sociedad multiétnica de la Reconquista (Moreno 1981: 257), por tanto, predispuso el traslado a tierras americanas de la cofradía grupal o étnica, aprovechando la existencia de la sociedad plural indiana. La teoría de la cofradía sintonizaba sobre todo con una sociedad indígena y campesina, de baja o nula estratificación interna, compatible con el reparto igualitario de cargas, y a la que, además, era posible controlar, tanto por parte de la Corona como de la Iglesia. La cofradía étnica debió ser una institución fundamental de la república de indios, de suerte que al mismo tiempo que se convertía en poderoso instrumento de colonización se constituía en auténtica expresión de la identidad indígena. Resultan bien expresivos de la rápida expansión de las cofradías étnicas por Iberoamérica durante el período colonial los trabajos de Celestino y Meyers (1981a y 1981b) a propósito de las cofradías de indios en Perú, y de Mena (2000) en relación con las cofradías de negros en Panamá. En un caso y en otro, la cofradía colonial fue una institución aplicada a la integración del indio desde el siglo XVI en el primer caso, y a la doble integración del negro, tanto libre como esclavo, en 
el caso de Panamá en el siglo XVII. Al mismo tiempo, a imagen y semejanza de lo que sucedía en España, las cofradías, colocadas al amparo de una devoción se convierten en expresiones nucleares de la vida local, tanto en la vertiente civil como en la religiosa, lo cual explicaría la condición cívico-religiosa que la generalidad de los antropólogos siguen atribuyendo a la institución en la actualidad, al menos desde Tax (1937). Así sucede, a título de ejemplo, con los trabajos de Cámara (1996 [1952]), Carrasco (1979 [1961]), Cancian (1996 [1967]), Sepúlveda (1974), Chance y Taylor (1985), Foster (1987) Korsbaek (1987), Topete (2009), etc.

En toda la América colonizada por los españoles debieron existir, al menos, cuatro medios de subvenir las necesidades económicas de la cofradía, que eran los bienes raíces y los semovientes, las donaciones, la colecta y el patronazgo, de idéntica manera a lo que sucedió históricamente en España. Sin embargo, y por lo que parece, los generosos incrementos de riqueza fueron convirtiendo a las cofradías en estructuras de poder, independizadas en parte de la administración política y de la eclesiástica. Con el precedente creado por la supresión de buena parte de las cofradías en Francia por parte de Turgot en 1776, según nos cuenta Abbad (1977: 365), la Administración borbónica intentó hacer lo propio con la ayuda de los obispos reformistas, en el marco de una interpretación típicamente regalista, considerando el arcaísmo de estas instituciones, la ocultación fiscal de las mismas y los derechos jurisdiccionales adquiridos por las cofradías en el transcurso del tiempo. Un reciente trabajo de Carbajal (2012) sobre la reforma borbónica de las cofradías novohispanas (1767-1820) explica cómo el Consejo de Indias trató de convertir las cofradías en cuerpos profanos, bajo la jurisdicción de la Corona y no del clero, sin renunciar a la espiritualidad que anidaba en las mismas.

El lento proceso de supresión de cofradías que tiene lugar desde finales del siglo XVIII, junto con la modificación de sus reglas, se completa progresivamente con la pérdida de las tierras que les sirven de sustento, por efecto de las sucesivas desamortizaciones que se producen en el siglo XIX. Este proceso se hace particularmente intenso en América en las décadas que siguen al nacimiento de las nuevas repúblicas, y particularmente en países como México, donde la Ley Lerdo de desamortización promulgada en 1856 y las llamadas leyes de reforma promulgadas por Benito Juárez en 1859, acompañadas por un fuerte proceso secularizador, marcaron la evolución de las cofradías. De nuevo hemos de recurrir a Palomo (2004: 154-155), que ha estudiado el caso de las cofradías de Chiapas en la época, para saber que fue entonces cuando se produjo una intensa transformación de las mismas para acomodarse a las circunstancias históricas de la segunda mitad del siglo XIX, justamente en un momento en el que muchas cofradías indígenas, cada vez más independizadas de los lazos que las habían atado a la Iglesia durante la colonia, estaban cargándose de poder, tratando de proteger unos recursos que, en ocasiones, eran abundantes. La manera que encontraron los pueblos indígenas de proteger los capitales piadosos de las cofradías, independizadas como se hallaban éstas de la Iglesia, y resultan muy significativos casos como el de la cofradía de San Francisco, administrada por el ayuntamiento de Amatenango (Palomo 2004: 163-171), consistió en situarlas bajo el amparo de los cabildos municipales, los cuales pasan a convertirse en titulares de iure de las mismas, fuera del alcance de las leyes desamortizadoras, y en permitir, simultáneamente, que las mismas siguieran siendo administradas de facto por los cofrades. 
No deja de ser curioso que el triunfo de las cofradías indígenas fuera el resultado de la presión que sobre las mismas realizaron los gobiernos federales. Si bien el objetivo de las leyes desamortizadoras y reformistas eran las propiedades eclesiásticas y las corporativas, es cierto que las cofradías indígenas chiapanecas presentaban mayor fortaleza patrimonial (debido a su sólida actitud identitaria y de resistencia, forjada especialmente en los primeros lustros de la República frente al poder del Estado), al revés que las cofradías de ladinos, más apegadas a la tradición eclesiástica española. Según avanza la segunda mitad del siglo XIX, las cofradías chiapanecas toman dos direcciones diferentes. La primera será la de las cofradías indígenas, amparadas y reforzadas por unos municipios que, a la vez que se sirven de la fortaleza política, económica y ritual de las mismas, comienzan a fundirlas institucionalmente con los ayuntamientos por medio del típico sistema de cargos o de una jerarquía cívico religiosa que desembocará en lo que es en la actualidad, con un característico reforzamiento de las estrategias sustanciadas en la colecta y, muy especialmente, en el patronazgo. La segunda será la de las cofradías ladinas, las cuales, cuando sobrevivieron, se orientaron hacia el fomento de la religiosidad y la piedad popular. En relación con lo que se acaba de señalar, el trabajo de John Chance y William Taylor (1985) relativo a Mesoamérica prueba meridianamente que la jerarquía cívico-religiosa que se registra en el área, cuya analogía con la andina resulta evidente, es un producto del siglo XIX, y de época republicana antes que de época colonial.

La existencia de la cofradía comporta una organización que supone el desempeño de funciones variadas por parte de los cofrades, como puede verse en el caso de las viejas cofradías parroquiales, o en el caso de las existentes en la actualidad, tanto en España como en Latinoamérica. Los cofrades con cometido organizativo de algún grado ostentan el correspondiente cargo, entendido éste como una carga o responsabilidad. Este término léxico, el de cargo, de uso muy extendido en la lengua española, es el que pasó a América desde los mismos inicios de la colonización. Tales cargos, al igual que ha sucedido tradicionalmente en las cofradías españolas, y aún continúa sucediendo en el presente, son temporales, de manera análoga a lo que acontece con la elección de los cargos u oficios en la jerarquía cívico-religiosa en nuestros días, y así lo subraya Carrasco (1979: 325). Y también, análogamente, en uno y otro caso, la escala progresa desde los rangos serviles de la base hasta la cúspide, de modo que, según nos acercamos a esta última los cargos entrañan mayores responsabilidades.

En este sentido, la contribución, el sufragio personal y el patronazgo también tienen cabida en las cofradías españolas, con el consiguiente reconocimiento general por parte de los demás cofrades, todo lo cual se traduce en un incremento del prestigio personal del benefactor, evidenciándose así la existencia de parecidos insoslayables entre las cofradías mesoamericanas y las españolas. El prestigio de los cargos, dado por su posición en la jerarquía, con el correspondiente reflejo en la representación externa y en la exhibición social, ha sido consustancial con las cofradías españolas desde sus orígenes medievales. Así lo demuestran los trabajos de Benítez (2006: 576-589) sobre las cofradías valencianas en los siglos XIV y XV y de Molina (2014) sobre las cofradías de pintores, bordadores y escultores de Mallorca en el siglo XVI. Este prestigio personal, susceptible de ser acumulado en torno a la cofradía, continúa 
manifestándose tanto en España como en la América hispana, lo cual parece guardar relación con el carácter institucional de la misma. Ésta es la idea sustentada por Foster $(1959,1962)$, especialmente en su texto sobre la cofradía, el gremio (al cual podríamos entender como una forma de cofradía), y el compadrazgo, cuando, tras establecer claras analogías entre la cofradía española y la mesoamericana, llega a la conclusión de que estamos ante un sistema corporativo orientado hacia la ayuda mutua, cuya carga institucional procede de su potencia para afrontar las crisis sociales (Foster 1959, 1987). La participación en el sistema se traduciría en la obtención de réditos sociales y prestigio personal.

Son muy numerosas las cofradías españolas que han sobrevivido al tiempo, dotadas de reglas que, en el marco del derecho canónico vigente, son renovadas periódicamente, conservando así muchas de las funciones que les dieron vida en el pasado: fomento del culto, difusión de la devoción, conservación del patrimonio religioso, participación en ritos y ceremonias, cumplimiento de la disciplina, cooperación en la hermandad, solidaridad entre los cofrades, etc. Todo cofrade, en el momento de su ingreso en la cofradía, frecuentemente siguiendo una tradición familiar, jura la regla de la misma, que le proporcionará, aparte de otros derechos, el de usar sus símbolos, convirtiéndole, simultáneamente, en sujeto de numerosas obligaciones.

En el presente el mejor ejemplo lo hallamos en España en las cofradías denominadas penitenciales, constituidas en torno a la Semana Santa. Cada cofradía está compuesta por una diversidad de cargos, debidamente ordenados, que se hallan al servicio de los principios religiosos y sociales o civiles que inspiran la asociación. Dentro de la variada casuística existente, y más allá de los hermanos cofrades que no poseen misión específica, los cargos más comunes en las cofradías españolas incluyen la existencia de capilleros, diputados (mayores, de formación, de obras asistenciales, etc.), priostes (primero, segundo, etc.), camareros y camareras, fiscal o consiliario, secretario (primero, segundo, etc.), mayordomos (primero, segundo, etc., cuyo ordinal lleva aparejadas sus correspondientes funciones: tesorería, contaduría, procesiones, pasos, culto, etc.), consiliarios, teniente del hermano mayor y hermano mayor, $\mathrm{y}$, dependiendo del caso, los cargos pueden ser muchos más. En aras del prestigio interno, algunas personas, con gran peso dentro de la cofradía, y que han ostentado el cargo de hermano mayor (alcalde, mayordomo, etc., según las denominaciones) pueden convertirse en hermano mayor de honor (mayordomos de honor, alcaldes antiguos, etc.). Simultáneamente, las cofradías españolas realizan nombramientos ad honorem en beneficio de personas, generalmente con un cierto reconocimiento público que, sin ser cofrades, unen a su particular prestigio el que les reporta el cargo de honor que les otorga la cofradía por un tiempo. Se conforma de este modo una organización cuya tesorería se nutre de las cuotas de los cofrades, así como de los donativos y, en su caso, de las aportaciones relacionadas con el patronazgo. De lo dicho se deduce que las cofradías mesoamericanas que se han examinado en este texto, y aún las cofradías de otras partes de la América hispana que se han mencionado, presentan similitudes estructurales y funcionales con las españolas que sugieren el inequívoco origen hispánico de aquéllas. 


\section{Conclusión}

Tras el análisis realizado del sistema de cargos mesoamericano en las líneas precedentes, se llega a la conclusión de que, frente a la tesis sostenida por Pedro Carrasco, consistente en atribuir a la jerarquía cívico-religiosa la continuidad de la tradición prehispánica, caben otras explicaciones más verosímiles. Así, sabemos con certeza que las estructuras sociales creadas por los colonizadores transformaron la sociedad $\mathrm{y}$, una vez institucionalizadas, se perpetuaron en el tiempo, como colonialidad del poder. Antes de su implantación en América, la cofradía, erigida inicialmente como fundación piadosa, había acabado por convertirse en una institución relevante de la sociedad española, gracias a su singular capacidad adaptativa. Tenemos la certeza de que la cofradía, análogamente, se constituiría en uno de los fundamentos de la refinada estrategia colonial y evangelizadora en una sociedad multiétnica como era la americana, lo cual daría pábulo a la integración segmentaria de los sectores indígenas en la organización social, marcadamente segregada, promovida por los colonizadores.

Simultáneamente, y de modo que el hecho ganara en eficacia, los grupos indígenas verían reconocida su identidad, hasta el extremo de hacer de la cofradía un instrumento de resistencia étnica. Fue así como la cofradía terminaría siendo una institución nuclear de la vida local indígena, revestida de un acusado carácter cívicoreligioso, gracias a su idoneidad para acoger determinadas funciones políticas, sociales y económicas, y a su fuerza para canalizar las identidades colectivas y crear una apariencia de cohesión social.

Las acometidas del poder real en la última fase del período colonial, y las del poder republicano a mediados del siglo XIX (laicización y desamortización), bien conocidas en el caso de México, provocaron una crisis en las cofradías, que fue paliada mediante el reforzamiento de su carácter civil, a la sombra del poder local, y mediante la potenciación de un recurso que ya había sido identificado con anterioridad, como era el patronazgo, el cual se erigiría en fuente principal del sostenimiento económico de la institución, $\mathrm{y}$, al mismo tiempo, en un referente inigualable de prestigio personal y de reputación social, trascendiendo asimismo la alta valoración que ya poseía en el pasado. Es así que, aun reconociendo la fuerte personalidad del sistema de cargos que cristalizó en la Mesoamérica del siglo XIX, y al que no son ajenos los sistemas de cofradías o de fiestas extendidos por tierras de la América hispana, y admitiendo la posible existencia de instituciones prehispánicas concurrentes, existen sobradas razones para atribuir un inequívoco origen hispánico a la institución, que adquirirá su fisonomía actual, por razones sobrevenidas, en el primer período republicano.

\section{Referencias bibliográficas}

ABBAD, Farid

1977 «La confrérie condamnée ou une spontanéité festiva confisquée. Un autre aspect de l’Espagne à la fin de l'Ancien Régime». Mélanges de la Casa de Velázquez 13: 361-384.

Aguirre Beltrán, Gonzalo

1953 Formas de gobierno indígena. México: Imprenta Universitaria. 
Benítez Bolorinos, Manuel

2006 «Las cofradías en el reino de Valencia. Análisis y claves interpretativas». Anuario de Estudios Medievales 36 (2): 553-581.

BuCHLER, Hans C.

1980 Aymara Fiestas and Social Interaccion in the Bolivian Highlands. The Hague: Mouton.

BuCHLER, Ira R. y Michael MCKINLAY

1996 «Procesos de decisión en la cultura. Un análisis de programación linear» [1969], en Introducción al sistema de cargos, Leif Korsbaek ed., pp. 226-248. Toluca: Universidad Autónoma del Estado de México.

CÁmara BARbaChano, Fernando

1996 «El sistema de cargos en México y Perú» [1952], en Introducción al sistema de cargos, Leif Korsbaek, comp., pp. 113-159. Toluca: Universidad Autónoma del Estado de México.

CANCIAN, Frank

1972 Change and Uncertainty in a Peasant Economy: The Maya Corn Farmers of Zinacantan. Stanford: Stanford University Press.

1976 Economía y prestigio en una comunidad maya: el sistema religioso de cargos en Zinacantán [1965]. México: CONACULTA, Instituto Nacional Indigenista.

1991 «El comportamiento económico en las comunidades campesinas» [1989], en Antropología Económica, Stuart Plattner, ed., pp. 177-234. México: CONACULTA, Alianza Editorial.

1996 «Organizaciones políticas y religiosas» [1967], en Introducción al sistema de cargos, Leif Korsbaek, comp., pp. 193-226. Toluca: Universidad Autónoma del Estado de México.

CARbajal López, David

2012 «La reforma de las cofradías novohispanas en el Consejo de Indias, 1767-1820». Revista Complutense de Historia de América 38: 79-101.

CARrasco, Pedro

1952 Tarascan Folk Religion. Nueva Orleans: Tulane University.

1975 «La transformación de la cultura indígena durante la colonia». Historia Mexicana 25 (2): 175-203.

1979 «La jerarquía cívicorreligiosa en las comunidades de Mesoamérica: antecedentes precolombinos y desarrollo colonial» [1961], en Antropología política, José R. Llobera, comp., pp. 323-340. Barcelona: Editorial Anagrama.

Celestino, Olinda y Albert Meyers

1981a Las cofradías en el Perú: región central. Frankfurt: Vervuert.

1981 b «La dinámica socio-económica del patrimonio cofradial en el Perú Colonial: Jauja en el siglo XVII. Revista Española de Antropología Americana 11: 183-206.

Chance, John K. y William B. Taylor

1985 «Cofradías y cargos. Una perspectiva histórica de la jerarquía cívico-religiosa mesoamericana». Antropología 14: 1-23. (Suplemento).

ChaYANov, Alexander

1974 La organización de la unidad económica campesina [1925]. Buenos Aires: Ediciones Nueva Visión. 
De WaLt, Billy

1996»Cambios en los sistemas de cargos de Mesoamérica» [1975], en Introducción al sistema de cargos, Leif Korsbaek, comp., pp. 249-270. Toluca: Universidad Autónoma del Estado de México.

DÉFOURNEAUX, Marcellin

1983 La vida cotidiana en España en el Siglo de Oro. Barcelona: Argos Vergara.

DuRÁN, fray Diego

1995 Historia de las Indias de Nueva España y islas de Tierra Firme, 2 vols. México: Consejo Nacional para la Cultura y las Artes

FAVRE, Henri

1973 Cambio y continuidad entre los mayas de México. México: Siglo XXI.

FosTER, George M.

1959 «Cofradía y compadrazgo en España e Hispanoamérica». Revista del Museo Nacional XXVIII: 248-276.

1962 Cultura y conquista: la herencia española de América. Xalapa: Universidad Veracruzana.

1967 «Peasant Society and the Image of Limited Good», en Peasant Society. A Reader, Jack M. Potter, May N. Díaz y George M. Foster, eds., pp. 320-323. Boston: Little Brown and Company.

1987 Tzintzuntzan. México: Fondo de Cultura Económica.

Gómez PELlón, Eloy

2011 Tierra, trabajo y conflicto en el campesinado. Santander: Universidad de Cantabria.

2016 «Variaciones en torno al concepto de aculturación», en Antropología, Cultura y Educación, Antonio J. Colom y Carmelo Lisón, eds., pp. 53-82. Valencia: Tirant lo Blanch.

HARris, Marvin

1964 Patterns of Race in the Americas. Nueva York: Walker and Co.

KORSBAEK, Leif

1987 «El desarrollo del sistema de cargos de San Juan Chamula: el modelo teórico de Gonzalo Aguirre Beltrán y los datos empíricos». Anales de Antropología 24: 215 242.

1990 «La religión y la política de cargos: una comparación de tres comunidades mayas en los Altos de Chiapas». Cuicuilco 23-24: 115-129.

KorSBAEK, Leif (ed.)

1996 Introducción al sistema de cargos. Toluca: Universidad Autónoma del Estado de México.

2009 Introducción crítica al sistema de cargos (en prensa).

Kroeber, Alfred Louis

1923 Anthropology (with supplement). Nueva York: Harcourt, Brace and Co.

1948 Anthropology. Race. Language, Culture, Psychology, Prehistory. Nueva York: Harcourt, Brace and Co.

LEWIS, Oscar

1951 Life in a Mexican Village. Tepoztlán Restudied. Urbana: University of Illinois Press. 
MACLEOD, Murdo J.

1983 «Papel social y económico de las cofradías indígenas de la colonia en Chiapas». Mesoamérica 5: 64-86.

Mena García, Carmen

2000 «Religión, etnia y sociedad: cofradías de negros en el Panamá colonial». Anuario de Estudios Americanos 57 (1): 137-169.

Mignolo, Walter

2003 Historias locales/diseños globales: colonialidad, conocimientos subalternos y pensamiento fronterizo. Madrid: Akal.

2007 La idea de América Latina. La herida colonial y la opción decolonial. Barcelona: Gedisa.

Molina Bergas, Francisco

2014 «Jerarquía y poder en la cofradía de pintores, bordadores y escultores de la ciudad de Mallorca (1590-1602)». Bolletí de la Societat Arqueològica Lulliana. Revista d'Estudis Històrics 70: 141-163.

MOREno NaVARro, Isidoro

1981 «Control político, integración ideológica e identidad étnica: el «sistema de cargos» de las comunidades indígenas americanas como adaptación de las cofradías étnicas andaluzas», en Primeras Jornadas de Andalucía y América, pp. 249-265. Huelva: Instituto de Estudios Onubenses.

NASH, Manning

1966 Primitive and Peasant Economic Systems. San Francisco: Chandler.

2009 «El contexto social de la toma de decisiones económicas en una sociedad pequeña» [1961], en Introducción crítica al sistema de cargos, Leif Korsbaek, ed., pp. 87-104 (en prensa).

Noriega Hope, Carlos

1922 «Apuntes etnográficos», en La población del valle de Teotihuacán, Manuel Gamio, comp., tomo 2, pp. 203-281. México: Dirección de Talleres Gráficos.

Palomo Infante, María Dolores

2001 «Cofradías y sistemas de cargos: algunas hipótesis sobre los orígenes y conformación histórica de las jerarquías cívico-religiosas entre los tzotziles y tzeltales de Chiapas». Pueblos y Fronteras 2: 143-155.

2004 «Tiempos de secularización: Iglesia y cofradías en Chiapas a partir de 1856», Mesoamérica 46: 153-172.

QuiJano, Aníbal

2000 «Colonialidad del poder, eurocentrismo y América Latina», en La colonialidad del saber: eurocentrismo y ciencias sociales. Perspectivas Latinoamericanas, Edgardo Lander comp., pp. 201-246. Buenos Aires: CLACSO.

2007 «Colonialidad y clasificación social» [2000], en El giro decolonial. Reflexiones para una diversidad epistémica más allá del capitalismo global, Santiago CastroGómez y Ramón Grosfoguel, eds., pp. 93-126. Bogotá: Siglo del Hombre Editores.

REDFIELD, Robert

1930 Tepoztlan, a Mexican Village. A Study in Folk Life. Chicago: University of Chicago Press. 
1973a The Little Community. Viewpoints for the Study of a Human Whole. [1955]. Chicago: The University of Chicago Press.

1973b Peasant Society and Culture. An Anthropological Approach to Civilization [1956]. Chicago: The University of Chicago Press.

Rumeu de Armas, Antonio

1944 Historia de la previsión social en España. Cofradias, gremios, hermandades, montepíos. Madrid: Editorial Revista de Derecho Privado.

Rus, Jan y Robert WaSSERSTROM

1980 «Civil-Religious Hierarchies in Central Chiapas: A Critical Perspective». American Ethnologist 7 (3): 466-478.

SAHAGún, fray Bernardino de

1938 Historia general de las cosas de Nueva España, 5 vols., (1540-1585). México: Pedro Robredo.

SEPúlvedA, María Teresa

1974 Los cargos políticos y religiosos en la región del Lago de Pátzcuaro. México: Colección Científica 19, Instituto Nacional de Antropología e Historia.

SMITH, Waldemar R.

1981 El sistema de fiestas y el cambio socio-económico [1977]. México: Fondo de Cultura Económica.

TAx, Sol

1937 «The municipios of the Midwestern Highlands of Guatemala». American Anthropologist 39 (3): 423-444.

TöNNIES, Ferdinand

2009 Comunidad y asociación. El comunismo y el socialismo como formas de vida social. Granada: Comares (1887).

TOPETE LARA, Hilario

2009 «El poder, los sistemas de cargos y la antropología política», en Introducción crítica al sistema de cargos, Leif Korsbaek, ed., pp. 87-104 (en prensa).

TsCHOPIK, Harry

1947 Highland Communities of Central Peru. A Regional Survey. Washington: Institute of Social Anthropology Pub. 5. Smithsonian Institution.

VINCENT, Catherine

1994 Les confréries médiévales dans le royaume de France: XIIIe-XVe siècle. Paris: Éditions Albin Michel.

Vogt, Evon Z.

1979 Ofrendas para los dioses. Análisis simbólico de rituales zinacantecos [1976]. México: Fondo de Cultura Económica.

Vogt, Evon Z. (ed.)

1966 Los zinacantecos, un pueblo tzotzil de los altos de Chiapas. México: Instituto Nacional Indigenista.

WASSERSTROM, Robert

1989 Clase y sociedad en el centro de Chiapas [1983]. México: Fondo de Cultura Económica. 
WoLF, Eric

1955 «Types of Latin American Peasantry: A Preliminary Discussion». American Anthropologist 57 (3): 452-471.

1971 Los campesinos [1966]. Barcelona: Editorial Labor.

1981 «Comunidades corporativas cerradas de campesinos de Mesoamérica y Java Central» [1957], en Antropología económica, José R. Llobera, comp., pp. 81-95. Barcelona: Editorial Anagrama. 